\title{
Effect and mechanism of resveratrol on drug resistance in human bladder cancer cells
}

\author{
SHANSHAN WANG ${ }^{1,2}$, QIAN MENG ${ }^{1,2}$, QING XIE ${ }^{1,2}$ and MAN ZHANG ${ }^{1-3}$ \\ ${ }^{1}$ Clinical Laboratory Medicine and ${ }^{2}$ Beijing Key Laboratory of Urinary Cellular Molecular Diagnostics, \\ Beijing Shijitan Hospital, Capital Medical University, Beijing 100038; ${ }^{3}$ Chinese Medical Doctor \\ Association of Lab Medicine, Chinese Medical Doctor Association, Beijing 100027, P.R. China
}

Received September 25, 2015; Accepted October 11, 2016

DOI: $10.3892 / \mathrm{mmr} .2017 .6111$

\begin{abstract}
Multidrug resistance (MDR) is a significant barrier to the effective treatment of bladder cancer. In order to improve the management of bladder cancer, it is crucial to identify strategies that may reverse MDR. The effects of three herbal medicines, ginsenoside Rh2, (-)-epigallocatechin gallate (EGCG) and resveratrol (RES) on bladder cancer were determined. The effect of these three herbal medicines against the drug resistance in adriamycin (ADM)-resistant pumc-91 cells (pumc-91/ADM) was assessed using the Cell Counting Kit-8 cell proliferation assay system. Cell cycle distribution analysis was performed using flow cytometry following treatment with RES. The mRNA and protein expression levels of multidrug resistance protein 1 (MRP1), lung resistance protein (LRP), glutathione S-transferase (GST), B cell leukemia/lymphoma-2 (BCL-2) and topoisomerase-II (Topo-II) were evaluated using reverse transcription-quantitative polymerase chain reaction and immunofluorescence, respectively. RES enhanced the cytotoxicity of anticancer agents on pumc-91/ADM cells; however, Rh2 and EGCG were unable to induce a similar effect. Additionally, RES treatment led to S phase cell cycle arrest accompanied by a decrease in the number of cells in the G1 phase. A significant decrease of MRP1, LRP, GST, BCL-2 levels and an increase of Topo-II levels were observed in RES groups compared with the control group. RES effectively reversed ADM resistance in pumc-91/ADM cells and the underlying molecular mechanism may be associated with the alteration of MRP1, LRP, GST, BCL-2 and Topo-II expression levels. Therefore, RES may be a potential candidate for reversing drug resistance in bladder cancer chemotherapy.
\end{abstract}

Correspondence to: Professor Man Zhang, Beijing Key Laboratory of Urinary Cellular Molecular Diagnostics, Beijing Shijitan Hospital, Capital Medical University, 10 Tieyi Road, Haidian, Beijing 100038, P.R. China

E-mail: mzhang99@aliyun.com

Key words: bladder cancer, herbal medicines, chemotherapy, drug resistance, reversal effect

\section{Introduction}

Globally, bladder cancer is the most common malignant tumor of the urogenital system, 35-45\% of bladder tumors will recur and $10 \%$ of patients will progress to muscle-invasive disease (1). It has been confirmed that intravesical chemotherapy may significantly reduce the frequency of tumor recurrence. Patients with muscle-invasive disease have a higher mortality risk due to distant metastases. For these patients, systemic chemotherapy treatment remains the primary clinical therapeutic strategy to improve their quality of life and prolong survival (2). However, chemoresistance, which occurs frequently, may lead to poor prognosis and is the main obstacle limiting the success of chemotherapy.

The resistance phenotype may be associated with tumor cells gaining cross-resistance to a variety of drugs with different molecular structures and targets, which is termed multidrug resistance (MDR) (3). Several mechanisms had been implicated in the development of MDR, including an increase in drug efflux, changes of protein expression levels, mutations that diminish the binding of the drug to the target, alterations in the metabolism of drugs, modification of cell cycle checkpoints, inactivation of the agents, increased DNA damage repair and defective apoptotic pathways (4-8).

MDR may occur due to variation in the expression levels of transporter proteins. Multidrug resistance protein 1 (MRP1) acts as an efflux pump, which rapidly extrudes various anticancer drugs from the target cancer cells $(9,10)$. The overexpression of MRP1 may decrease the intracellular concentration and cellular cytotoxicity of various anticancer drugs, including adriamycin, vinblastine, mitoxantrone and etoposide (11-14). Lung resistance protein (LRP) mediates drug resistance by transporting drugs from the nucleus to the cytoplasm through vesicular trafficking, thus reducing the cytotoxicity of drugs (15). Glutathione S-transferase (GST) is important for the development of drug resistance via direct detoxification; therefore, it may also decrease the concentration of anticancer drugs via the GSH-conjugate export pump $(16,17)$. Topoisomerase-II (Topo-II) is the primary target for various anticarcinogens, including anthracyclines, epipodophy and amsacrine. These drugs interfere with DNA replication and promote DNA strand breaks via forming drug-Topo-II-DNA complexes in cancer cells. Reduced activity 
and sensitivity of Topo-II is crucial for the development of drug resistance (18). B cell leukemia/lymphoma-2 (BCL-2) is considered to be one of the primary anti-apoptotic proteins. In H69AR adriamycin-resistant human small cell lung cancer cells infected with BCL-2 interfering RNA, the expression level of BCL-2 was reduced and the cells were more sensitive to daunomycin compared with the parental cells (19).

It has been previously reported that various therapeutic agents have been entered into clinical trials, such as verapamil, quinine and tariquidar. However, they have had limited therapeutic efficacy during the trials due to several barriers. The clinical failure of MDR modulators may be attributed to their non-specific toxicity to patients with cancer. Another factor may be the unexpected pharmacokinetic interactions between the modulators and the anticancer drugs. These unexpected pharmacokinetic interactions may lead to the reduction of anticarcinogen doses and result in inefficient treatment of patients (20). Furthermore, these agents often have only one target. Therefore, the identification of novel MDR mediators with low toxicity, high efficiency and multiple targets, which may reverse the drug resistance to satisfy the requirement of clinical applications is urgently required.

Herbal medicines are important therapeutic agents, with pharmaceutical potential (21). The use of herbal medicines has become increasingly popular, particularly in patients with cancer that exhibit chemotherapy resistance (22). This approach may be a complementary and alternative approach to chemotherapy. Due to the narrow therapeutic window of chemotherapy drugs, a synergistic effect may improve the therapeutic effects and reverse drug resistance that may occur as a result of long-term chemotherapy. A previous study demonstrated that ginsenoside $\mathrm{Rh} 2(\mathrm{Rh} 2)$, (-)-epigallocatechin gallate (EGCG) and resveratrol (RES) may have strong reversal effects on various types of cancer (23-25). Rh2 is an important active ingredient in ginseng (26). EGCG is a major component extracted from green tea. Previous studies have reported that EGCG has inhibitory activity against tumorigenesis $(27,28)$. RES, also termed trans-3,4',5-trihydroxystilbene, is a naturally occurring phytoalexin. It is obtained from multiple plant species, including peanuts, mulberries, and particularly in the peel of grapes used for red wine production (29). A previous study verified that RES was capable of enhancing the cytotoxicity of chemotherapeutic agents by reversing the MDR of MCF-7/DOX cells in response to doxorubicin (23). However, to the best of our knowledge, this is the first study to investigate reversing drug resistance using Rh2, EGCG and RES in bladder cancer chemotherapy.

The present study examined the effect of Rh2, EGCG and RES on cell viability in the MDR pumc-91/ADM human bladder cancer cell line. The reversal effects of these three herbal medicines were determined. The molecular mechanisms behind the reversal effect of RES in pumc-91/ADM cells on MDR were also investigated.

\section{Materials and methods}

Cell culture. Prior to cell culture, all experiment components were autoclaved at $120^{\circ} \mathrm{C}$ for $60 \mathrm{~min}$. The subsequent cell manipulations were all performed in a sterile flow hood. The pumc-91 human bladder cancer cell line was provided by the Cell Laboratory of Peking Union Medical College Hospital (Beijing, China). Pumc-91/ADM cell line is an adriamycin drug-resistant cell line that was established by stepwise exposure of pumc-91 cells to increased concentrations of adriamycin (Aladdin Bio-Chem Technology Co., Ltd., Shanghai, China), starting from 0.02 to $1 \mu \mathrm{g} / \mathrm{ml}$ for $>6$ months. When the concentration of ADM was $1 \mu \mathrm{g} / \mathrm{ml}$, pumc-91/ADM cells were able to proliferate steadily with a $>90 \%$ survival rate. The establishment and evaluation of biological characteristics human multidrug-resistant bladder cancer pumc-91/ADM cell line have been previously described (30). The drug-resistant characteristics of the pumc-91/ADM cell line were confirmed using a cell viability assay, reverse transcription-quantitative polymerase chain reaction (RT-qPCR) and flow cytometry. The pumc-91 cell line was cultured in RPMI-1640 medium (Gibco; Thermo Fisher Scientific, Inc., Waltham, MA, USA), supplemented with $10 \%$ heat-inactivated fetal bovine serum (FBS; Dingguo Changsheng Biotechnology Co., Ltd., Beijing, China). The pumc-91/ADM cells were cultured in the aforementioned medium, supplemented with $18 \%$ FBS. The cells were maintained in a humidified incubator at $37^{\circ} \mathrm{C}$ supplied with $5 \% \mathrm{CO}_{2}$. All experiments were performed when the cells were in the exponential growth phase.

Cell viability assay. The effects of Rh2, EGCG and RES on the viability of pumc-91/ADM cells were determined using the Cell Counting Kit-8 (CCK-8) (Dojindo Molecular Technologies, Inc., Shanghai, China). A total of $8.0 \times 10^{3}$ cells/well were seeded into 96-well plates. Following overnight incubation, the cells were incubated with various concentrations of $\operatorname{Rh} 2(0,20,40,60,80,100 \mu \mathrm{M}$; Maestro Co., Ltd., Shanghai, China), EGCG (0, 40, 80, 120, 160, $200 \mu \mathrm{M}$; Sigma-Aldrich; Merck Millipore, Darmstadt, Germany) and RES $(0,50,100,150,200,250,300,350 \mu \mathrm{M}$; Sigma-Aldrich; Merck Millipore) which were dissolved in dimethylsulfoxide at a final concentration $<0.1 \%$. The structure of the three herbal compounds is presented in Fig. 1. The purities of RES, Rh2 and EGCG were $98 \%,>98 \%$ and $>95 \%$, respectively. RES was classified as reagent grade. Rh2 was classified as standard substance grade. EGCG was classified as biological reagent grade. RPMI-1640 culture medium with pumc-91/ADM cells was used as a negative control, whereas RPMI-1640 culture medium without cells served as a vehicle control. Following treatment with Rh2, EGCG and RES for 24, 48 and $72 \mathrm{~h}, 10 \mu \mathrm{l} \mathrm{CCK}-8$ solution was added to each well. The cells were incubated for $2 \mathrm{~h}$ at $37^{\circ} \mathrm{C}$ and the absorbance was determined using a microplate reader (Model 680; Bio-Rad Laboratories, Inc., Hercules, CA, USA) at wavelengths of 450 and $655 \mathrm{~nm}$. Experiments were performed in triplicate. The proliferation ratio was calculated using the following equation: Proliferation ratio $(\%)=\left(\mathrm{OD}_{\text {drug treated group }}-\mathrm{OD}_{\text {control }}\right.$ group $) /\left(\mathrm{OD}_{\text {control group }}-\mathrm{OD}_{\text {vehicle group }}\right)$. The half maximal inhibitory concentration $\left(\mathrm{IC}_{50}\right)$ was defined as the concentration of the drug that resulted in 50\% inhibition of cell growth. $\mathrm{IC}_{50}$ was obtained via regression analysis between drug concentrations and the cell inhibition rate using SPSS software version 17.0 (SPSS Inc., Chicago, USA).

Resistance reversal assay. The MDR reversal effect of Rh2, EGCG and RES on pumc-91/ADM cells was also detected 
using CCK-8. To minimize the reductive effect of Rh2, EGCG and RES on cell growth, lower concentrations were selected for the reversal experiments. Cells seeded into 96-well plates and then treated with various concentrations of ADM $(0,4,8,12,16,20,24,28,32,36 \mu \mathrm{g} / \mathrm{ml})$ in the presence of $\mathrm{Rh} 2$ $(0,5,10,20 \mu \mathrm{M}), \operatorname{EGCG}(0,10,20,40 \mu \mathrm{M})$ and $\operatorname{RES}(0,10,50$, $100 \mu \mathrm{M})$ for $48 \mathrm{~h}$. As aforementioned, $10 \mu \mathrm{l}$ of CCK-8 solution was added to each well. The absorbance was recorded at 450 and $655 \mathrm{~nm}$ wavelength following cell incubation at $37^{\circ} \mathrm{C}$ for $2 \mathrm{~h}$.

The reversal fold (RF) values were used as potency parameters of Rh2, EGCG and RES, and were calculated by dividing $\mathrm{IC}_{50}$ of $\mathrm{ADM}$ alone by the $\mathrm{IC}_{50}$ of $\mathrm{ADM}$ in combination with Rh2, EGCG or RES treatment. The combinational index $(\mathrm{CI})$ was calculated using the following formula: $\mathrm{CI}=(\mathrm{Ea}+\mathrm{b}) /(\mathrm{Ea}+\mathrm{Eb}-\mathrm{EaxEb})(23) . \mathrm{Ea}+\mathrm{b}$ represented the inhibition rate of ADM in combination with Rh2, EGCG or RES treatment. Ea represented the individual inhibition rate of $\mathrm{Rh} 2, \mathrm{EGCG}$ or RES and Eb represented the inhibition rate of ADM only. The nature of the drug interaction was defined as: i) Additive (+) if CI ranged from 0.85 to 1.15 ; ii) synergism (++) if CI ranged from 1.15 to 2.0 ; iii) subtraction (-) if CI ranged from 0.85 to 0.55 ; and iv) antagonism (--) when the CI was $<0.55$.

Cell cycle distribution analysis. Pumc-91/ADM cells were plated in culture dishes at a confluence level of 50-60\%. The medium was replaced with fresh RPMI medium containing different concentrations of $\operatorname{RES}(0,10,50$ and $100 \mu \mathrm{M})$ after $24 \mathrm{~h}$. Following $48 \mathrm{~h}$ incubation with RES the cells were washed twice with cold Dulbecco's phosphate-buffered saline (D-PBS; Invitrogen; Thermo Fisher Scientific, Inc.) and then centrifuged at $140 \times \mathrm{g}$ for $5 \mathrm{~min}$ at $4^{\circ} \mathrm{C}$. The pellets were fixed with $70 \%$ ethanol in D-PBS and stored at $4^{\circ} \mathrm{C}$ overnight. Prior to analysis, cells were washed with D-PBS, centrifuged at $140 \times \mathrm{g}$ and resuspended with propidium iodide solution (0.05 mg/ml; Sigma-Aldrich; Merck Millipore) containing RNase $(100 \mu \mathrm{g} / \mathrm{ml})$. Subsequently, the cells were incubated in the dark at room temperature for $30 \mathrm{~min}$. The DNA content was analyzed using the FACSCalibur flow cytometer with CellQuest software version 3.0 (BD Biosciences, San Jose, CA, USA) at an excitation wavelength of $530 \mathrm{~nm}$. The data was analyzed using ModFit software version 3.2 (Verity Software House, Topsham, ME, USA).

RT-qPCR. Pumc-91/ADM cells were treated with RES $(0,10,50$ and $100 \mu \mathrm{M})$. Following incubation for $48 \mathrm{~h}$, the cells were harvested and total RNA was isolated with TRIzol reagent (Ambion; Thermo Fisher Scientific, Inc.) according to the manufacturer's protocol. Total RNA $(2 \mu \mathrm{g})$ was reverse transcribed using Oligo d(T) primers (Dingguo Changsheng Biotechnology Co., Ltd.), dNTPs (Gen-View Scientific, Inc., Beijing, China) and incubated with M-MLV reverse transcriptase for $1 \mathrm{~h}$ at $42^{\circ} \mathrm{C}$ (Promega Corporation, Madison, WI, USA). qPCR was performed using TransStart Top Green qPCR SuperMix (TransGen Biotech Co., Ltd., Beijing, China) with a LightCycler 480 Real Time PCR system (Roche Diagnostics, Basel, Switzerland). The PCR primer sequences used were as follows: GAPDH forward (F) 5'-TTTGGTATCGTGGAAGGA CT-3' and reverse (R) 5'-AGTAGAGGCAGGGATGATGT-3'; MRP1 F 5'-TTGCCGTCTACGTGACCATT-3' and R 5'-AGG
CGTTTGAGGGAGACACT-3'; LRP F 5'-TATGTGCCATCT GCCAAA GT-3' and R 5'-CATGTAGGTGCTTCCAATCA-3'; GST F 5'-TTCCTGTGGCATAATGTGAT-3' and R 5'-CTG ATTCAAAGGCAAATCTC-3'; Topo-II F 5'-AGGCATCGC ATCTTGTTTAG-3' and R 5'-CTGTCTCCGGTCTTCCAT AA-3'; and Bcl-2 F 5'-GACAACATCGCCCTGTGGAT-3' and R 5'-AGGGCCAAACTGAGCAGAGT-3'. The amplification conditions were as follows: $94^{\circ} \mathrm{C}$ for $5 \mathrm{~min} ; 45$ cycles of $10 \mathrm{sec}$ at $95^{\circ} \mathrm{C}, 10 \mathrm{sec}$ at $60^{\circ} \mathrm{C}$ and $10 \mathrm{sec}$ at $72^{\circ} \mathrm{C}$; a melting curve step of $5 \mathrm{sec}$ at $95^{\circ} \mathrm{C}, 1 \mathrm{~min}$ at $65^{\circ} \mathrm{C}$; then melting at $0.11^{\circ} \mathrm{C} / \mathrm{sec}$ with continuous acquisition mode until $97^{\circ} \mathrm{C}$; and a final cooling step at $4^{\circ} \mathrm{C}$ for $30 \mathrm{sec}$. In addition, the mRNA level of the reference gene GAPDH was determined and used to normalize the mRNA levels of drug resistance related genes. Relative gene expression was calculated using the $2^{-\Delta \Delta \mathrm{Cq}}$ method (31). All of the experiments were repeated at least three times.

Immunofluorescence assay. To assess the molecular mechanism underlying the reversal effect of RES in pumc-91/ADM cells, the protein expression levels of MRP1, LRP, GST, BCL-2 and Topo-II were assessed by immunofluorescence. Cells in the exponential phase were seeded on a glass slide at the density of $1.0 \times 10^{5}$ cells $/ \mathrm{ml}$. Following RES treatment $(0,10,50$ and $100 \mu \mathrm{M})$ for $48 \mathrm{~h}$, the cells were washed three times with PBS (Sijiqing Biological Engineering Materials Co., Ltd., Hangzhou, China) and then fixed with $4 \%$ paraformaldehyde (Dingguo Changsheng Biotechnology Co., Ltd.) for $15 \mathrm{~min}$ at room temperature. Cells were permeabilized using 0.1\% Triton X-100/PBS (Sigma-Aldrich; Merck Millipore) for 10 min and washed with PBS. Next, the cells were incubated with $10 \%$ goat serum (Dingguo Changsheng Biotechnology Co., Ltd.) for $1 \mathrm{~h}$ at $37^{\circ} \mathrm{C}$. The primary antibodies were diluted in $10 \%$ goat serum at $37^{\circ} \mathrm{C}$ for $2 \mathrm{~h}$. Slides were incubated with mouse monoclonal anti-MRP1 (cat. no. ab24102; 1:100), rabbit monoclonal anti-LRP (cat. no. ab175239; 1:100), rabbit polyclonal anti-GST (cat. no. ab9085; 1:250), rabbit monoclonal anti-BCL2 (cat. no. ab32124; 1:200), rabbit polyclonal anti-Topo-II (cat. no. ab74715; 1:500), all were obtained from Abcam (Cambridge, UK) for $1 \mathrm{~h}$ at $37^{\circ} \mathrm{C}$. Following the incubation with primary antibodies, the cells were washed with PBS three times, and then stained with AlexaFluor 488-conjugated secondary antibody [goat anti-mouse (cat. no. ab150117) and goat anti-rabbit (cat. no. ab150077) IgG; Abcam; $1: 400$ ) at $37^{\circ} \mathrm{C}$ in a moist cassette for $1 \mathrm{~h}$. The cells were washed with PBS three times and then incubated with $5 \mu \mathrm{g} / \mathrm{ml}$ Hoechst 33342 for $10 \mathrm{~min}$ at room temperature. Cell images were subsequently captured using fluorescence microscopy (Nikon 80i; Nikon Corporation, Tokyo, Japan; magnification, x400).

Statistical analysis. Statistical analysis was performed using SPSS 17.0 software. Data are presented as the mean \pm standard deviation. One-way analysis of variance was used to detect statistical significance between the control group and drug treatment groups. $\mathrm{P}<0.05$ was considered to indicate a statistically significant difference.

\section{Results}

Growth inhibitory effect of three herbal medicines on pumc-91/ADM cells. It was demonstrated that RES reduced the 
A<smiles>Oc1ccc(C=Cc2cc(O)cc(O)c2)cc1</smiles>

B

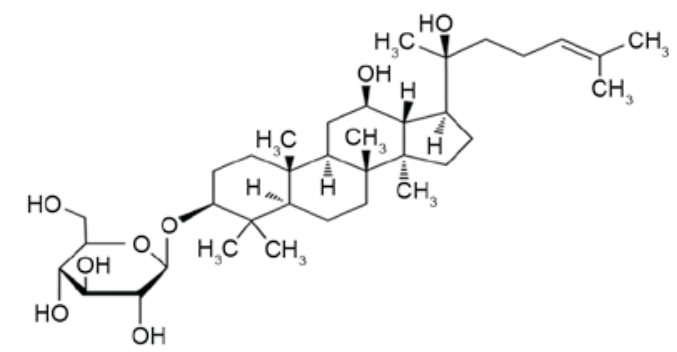

C<smiles>O=C(O[C@H]1Cc2c(O)cc(O)cc2O[C@@H]1c1cc(O)c(O)c(O)c1)c1cc(O)c(O)c(O)c1</smiles>

Figure 1. Chemical structures of three herbal medicines. (A) Resveratrol, $\mathrm{C}_{14} \mathrm{H}_{12} \mathrm{O}_{3}$, (B) ginsenoside $\mathrm{Rh} 2, \mathrm{C}_{36} \mathrm{H}_{62} \mathrm{O}_{8}$ and (C) (-)-epigallocatechin gallate, $\mathrm{C}_{22} \mathrm{H}_{18} \mathrm{O}_{11}$.
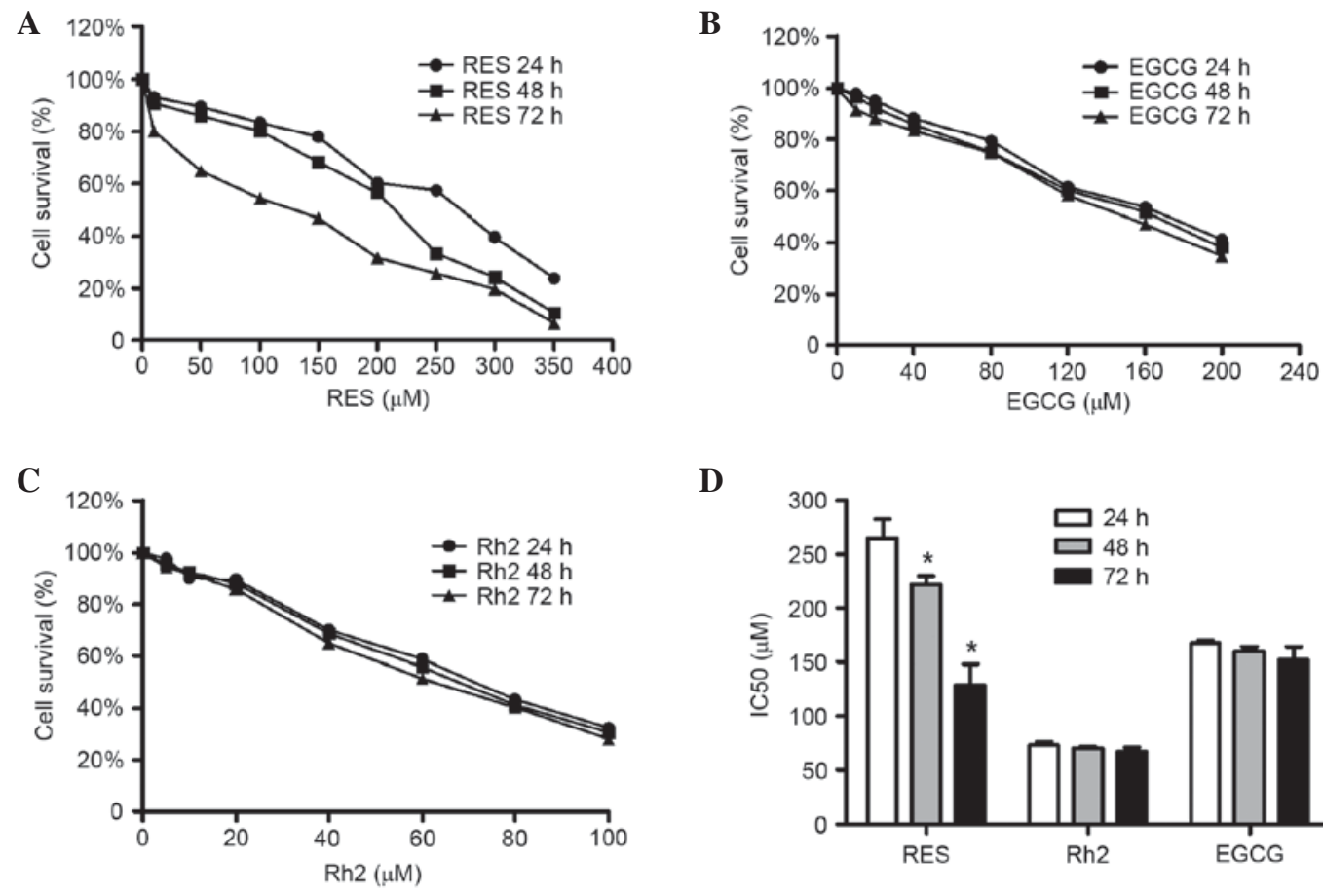

D

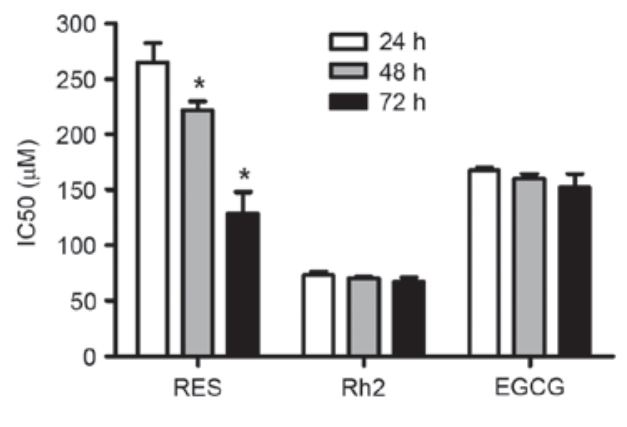

Figure 2. Inhibitory effect of three herbal medicines on pumc-91/ADM cells. Cell survival curves of (A) RES, (B) EGCG and (C) Rh2 for 24,48 and 72 h.(D) IC 50 values of these three herbal medicines at different times. $\mathrm{P}<0.05$ vs. RES $24 \mathrm{~h}$ group. RES, resveratrol; Rh2, ginsenoside Rh2; EGCG, (-)-epigallocatechin gallate.
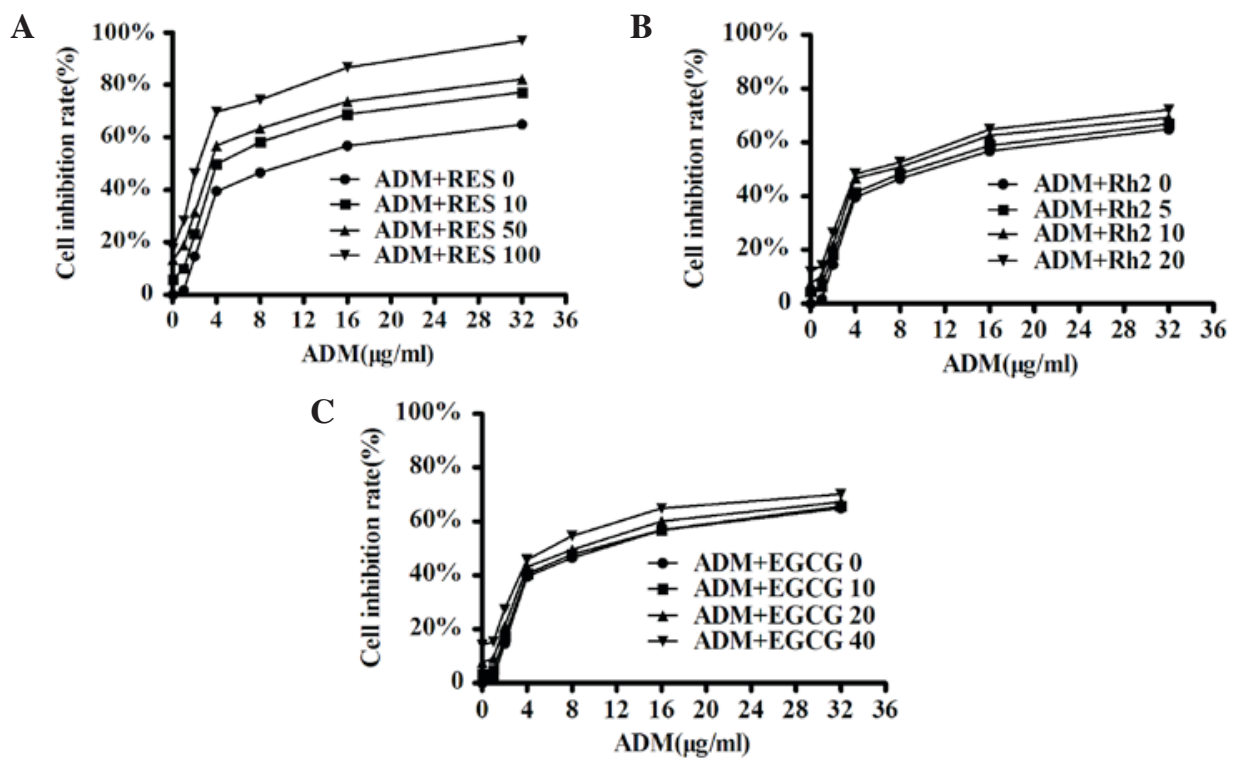

Figure 3. Effect of three herbal medicines on ADM cytotoxicity in pumc-91/ADM cells. A range of 1 to $32 \mu \mathrm{g} / \mathrm{ml}$ ADM was added to pumc-91/ADM cells with (A) RES $(0,10,50$ and $100 \mu \mathrm{M})$, (B) Rh2 $(0,5,10$ and $20 \mu \mathrm{M})$ or (C) EGCG $(0,10,20$ and $40 \mu \mathrm{M})$ for $48 \mathrm{~h}$. ADM, adriamycin; RES, resveratrol; Rh2, ginsenoside Rh2; EGCG, (-)-epigallocatechin gallate. 
Table I. Effect of RES, Rh2 and EGCG on ADM cytotoxicity in pumc-91/ADM cells.

\begin{tabular}{lccc}
\hline Group & $\mathrm{IC}_{50}(\mu \mathrm{g} / \mathrm{ml})$ & $\mathrm{RF}$ & $\mathrm{CI}$ \\
\hline ADM & 11.56 & 1.00 & N/A \\
ADM + RES 10 & $6.38^{\mathrm{a}}$ & $1.81^{\mathrm{a}}$ & 1.19 \\
ADM + RES 50 & $4.37^{\mathrm{a}}$ & $2.65^{\mathrm{a}}$ & 1.20 \\
ADM + RES 100 & $2.05^{\mathrm{a}}$ & $5.63^{\mathrm{a}}$ & 1.41 \\
ADM + Rh2 5 & 10.21 & 1.13 & 1.00 \\
ADM + Rh2 10 & 8.40 & 1.38 & 1.05 \\
ADM + Rh2 20 & 7.10 & 1.63 & 1.04 \\
ADM + EGCG 10 & 10.94 & 1.06 & 0.98 \\
ADM + EGCG 20 & 9.44 & 1.22 & 0.99 \\
ADM + EGCG 40 & 7.55 & 1.53 & 1.00
\end{tabular}

${ }^{\mathrm{a}} \mathrm{P}<0.05$ vs. control group (ADM). RES, resveratrol; Rh2, ginsenoside; EGCG, (-)-epigallocatechin gallate; ADM, adriamycin; $\mathrm{IC}_{50}$, half maximal inhibitory concentration; RF, reversal fold; CI, combine index.

Table II. Cell cycle analysis of pumc-91/ADM cells treated with resveratrol.

\begin{tabular}{rccr}
\hline Resveratrol $(\mu \mathrm{M})$ & $\mathrm{G} 1$ & $\mathrm{~S}$ & $\mathrm{G} 2$ \\
\hline 0 & 71.87 & 15.84 & 12.30 \\
10 & $52.93^{\mathrm{a}}$ & $34.45^{\mathrm{a}}$ & 12.61 \\
50 & $47.98^{\mathrm{a}}$ & $42.65^{\mathrm{a}}$ & 9.37 \\
100 & $40.66^{\mathrm{a}}$ & $50.67^{\mathrm{a}}$ & 8.67 \\
\hline
\end{tabular}

Values are expressed as $\%$ of the total cell population. ${ }^{\mathrm{a}} \mathrm{P}<0.01$ vs. control (RES $0 \mu \mathrm{M})$.

survival of pumc-91/ADM cells in a dose and time-dependent manner (Fig. 2A). As the RES concentration was increased cell survival gradually decreased. When cells were treated with RES at concentrations 10 to $350 \mu \mathrm{M}$ for $24 \mathrm{~h}$, the cell survival rate in pumc-91/ADM cells ranged from 6.9 to $76.1 \%$, whereas for 48 and $72 \mathrm{~h}$ ranged from 9.3 to $89.4 \%$, 20.0 to $93.4 \%$, respectively (Fig. 2A). EGCG and Rh2 were able to inhibit the proliferation of pumc-91/ADM cells in a dose-dependent manner; however, no time-dependent effects were observed (Fig. 2B and C). The RES IC $\mathrm{I}_{50}$ at 24, 48 and $72 \mathrm{~h}$ were estimated to be 265,222 and $129 \mu \mathrm{M}$, respectively. The RES $\mathrm{IC}_{50}$ values (24, 48 and $72 \mathrm{~h} ; 265,222$ and $129 \mu \mathrm{M}$, respectively) were significantly reduced when treatment was performed for 48 and $72 \mathrm{~h}$ compared with $24 \mathrm{~h}(\mathrm{P}<0.05)$. There were no significant differences between the $\mathrm{IC}_{50}$ values of $\mathrm{Rh} 2$ (24, 48 and $72 \mathrm{~h} ; 73,70$ and $67 \mu \mathrm{M}$, respectively; $\mathrm{P}>0.05)$ and EGCG (24, 48 and $72 \mathrm{~h} ; 167,160$ and $152 \mu \mathrm{M}$, respectively; $\mathrm{P}>0.05$ ) (Fig. 2D).

Reversal effects of Rh2, EGCG and RES on pumc-91/ADM cell line. Among the three herbal medicines investigated, RES was identified to have the most potent resistance reversal effect on pumc-91/ADM cells (Fig. 3A). No reversal effect was observed using EGCG or Rh2 (Fig. 3B and C). The $\mathrm{IC}_{50}$ values of ADM in combination with RES, Rh2 or EGCG for pumc-91/ADM cells are presented in Table $\mathrm{I}$. The $\mathrm{IC}_{50}$ of ADM in the RES treatment groups was significantly reduced compared with the control group $(\mathrm{P}<0.05$; Table I). The RF was increased by 1.81-fold when $10 \mu \mathrm{M}$ RES was used, increased 2.65 -fold with $50 \mu \mathrm{M}$ RES and increased 5.63-fold with $100 \mu \mathrm{M}$ RES. The CI was $1.19,1.20$ and 1.41 in the 10,50 and $100 \mu \mathrm{M}$ RES-treated groups, respectively (Table I). These findings demonstrated that RES had a reversal effect on the ADM resistance of pumc-91/ADM cells in a dose-dependent manner.

However, RF was 1.13, 1.38, 1.63-fold in the presence of $\mathrm{Rh} 2(5,10$ and $20 \mu \mathrm{M}$, respectively) and 1.06, 1.22, 1.53-fold in the presence of EGCG (10, 20 and $40 \mu \mathrm{M}$, respectively). The $\mathrm{CI}$ was 1.00, 1.05, 1.04 in Rh2 groups at the concentrations of 5,10 and $20 \mu \mathrm{M}$, respectively, and 0.98, 0.99, 1.00 in EGCG groups at the concentrations of 10,20 and $40 \mu \mathrm{M}$, respectively (Table I). These findings indicated that Rh2 and EGCG did not have an effect on the resistance of pumc-91/ADM cells.

RES treatment arrests the cell cycle in $S$ phase. Pumc-91/ADM cells were incubated with RES for $48 \mathrm{~h}$ and the effect of RES on cell cycle distribution was examined. The RES (10,50 and $100 \mu \mathrm{M})$ treatment groups had a significantly higher percentage of cells in S phase $(34.45,42.65$ and $50.67 \%$, respectively, vs. $15.84 \%$ ) compared with the control group (Fig. 4 and Table II). The increase in the $\mathrm{S}$ phase cell population was accompanied by a decrease in the number of pumc-91/ADM cells in the G1 phase.

Effects of RES on mRNA levels of MRPI, LRP, GST, BCL-2 and Topo-II in pumc-91/ADM cells. The expression levels of MRP1, LRP, GST, BCL-2 and Topo-II in pumc-91/ADM cells treated with different concentrations of RES were analyzed using RT-qPCR to determine whether their mRNA expression levels may be involved in the effect of RES on MDR. RES treatment led to a significant decrease of MRP1, LRP, GST, BCL-2 expression levels compared with the control group $(\mathrm{P}<0.05$; Fig. 5A) and a significant increase of Topo-II expression levels compared with the control group $(\mathrm{P}<0.05$; Fig. 5B). The levels of mRNA in the 10, 50 and $100 \mu \mathrm{M}$ RES-treated groups were 0.37 -fold, 0.10 -fold and 0.05 -fold lower then the control for MRP1, respectively. GST mRNA levels were 0.34-fold, 0.23 -fold and 0.08-fold lower than the control (10, 50 and $100 \mu \mathrm{M}$ RES, respectively). BCL-2 mRNA levels were 0.48 -fold, 0.27 -fold and 0.16 -fold lower than the control (10,50 and $100 \mu \mathrm{M}$ RES, respectively), and LRP mRNA levels were 0.72-fold, 0.44-fold and 0.24-fold lower than the control (10, 50 and $100 \mu \mathrm{M}$ RES, respectively; Fig. 5A). The decreases were statistically significant $(\mathrm{P}<0.05)$ and dose-dependent in the RES-treated groups. The expression levels of Topo-II following RES treatment were significantly increased compared with the control group ( $\mathrm{P}<0.05$; Fig. 5B). The expression levels of Topo-II mRNA were 2.7-fold higher in the $10 \mu \mathrm{M}$ RES group, 7.46-fold higher in the $50 \mu \mathrm{M}$ RES group and 15.0-fold higher in the $100 \mu \mathrm{M}$ RES group.

Effects of RES on the protein levels of MRPI, LRP, GST, $B C L-2$ and Topo-II in pumc-91/ADM cells. In order to determine whether the changes in mRNA expression levels 
A

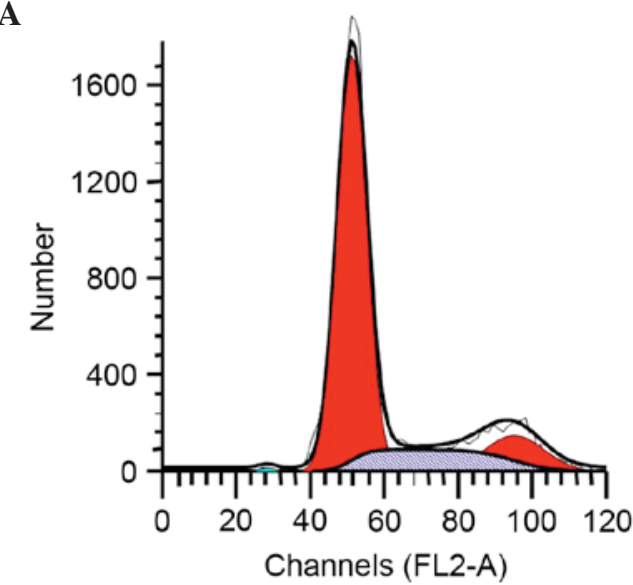

C

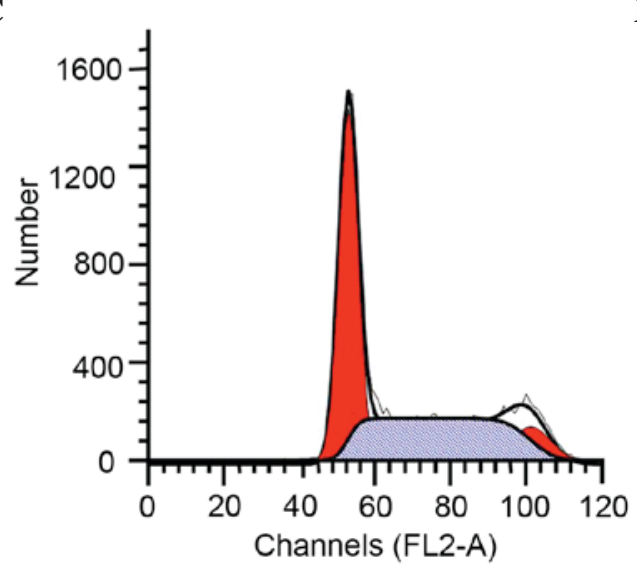

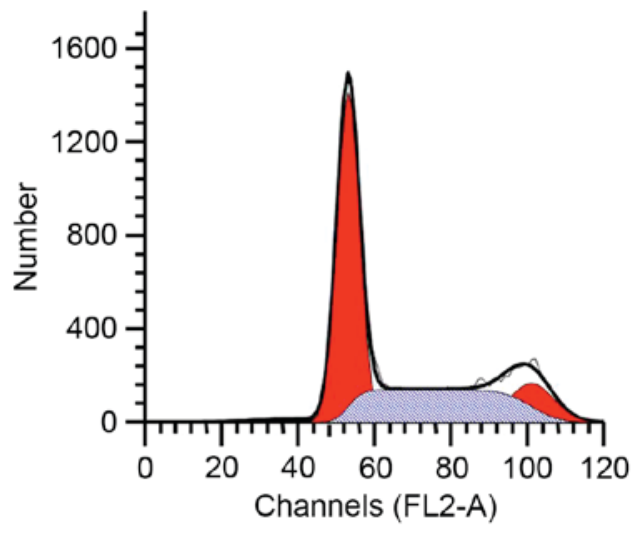

D

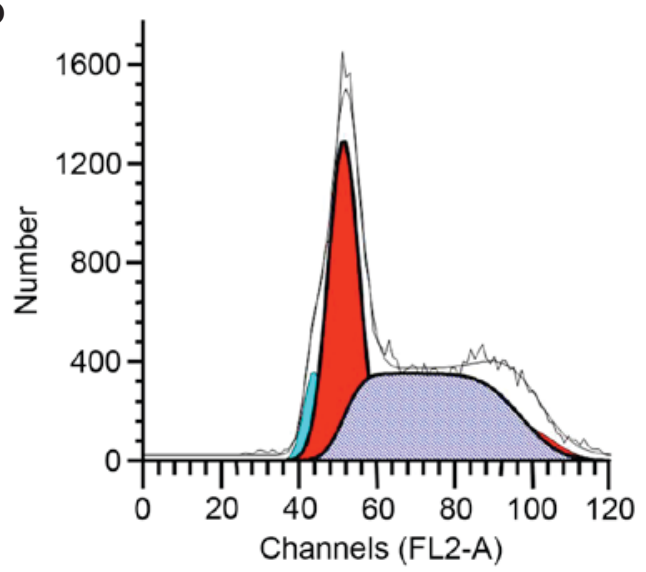

Figure 4. Cell cycle analysis of pumc-91/ADM cells treated with RES using flow cytometry. Cells were cultured with (A) $0 \mu \mathrm{M}$, (B) $10 \mu \mathrm{M}$, (C) $50 \mu \mathrm{M}$ and (D) $100 \mu \mathrm{M}$ RES for $48 \mathrm{~h}$. G1, S and G2 indicated cell cycle phases. G1, red on the left-hand side; S, gray; G2, red on the right-hand side.

A

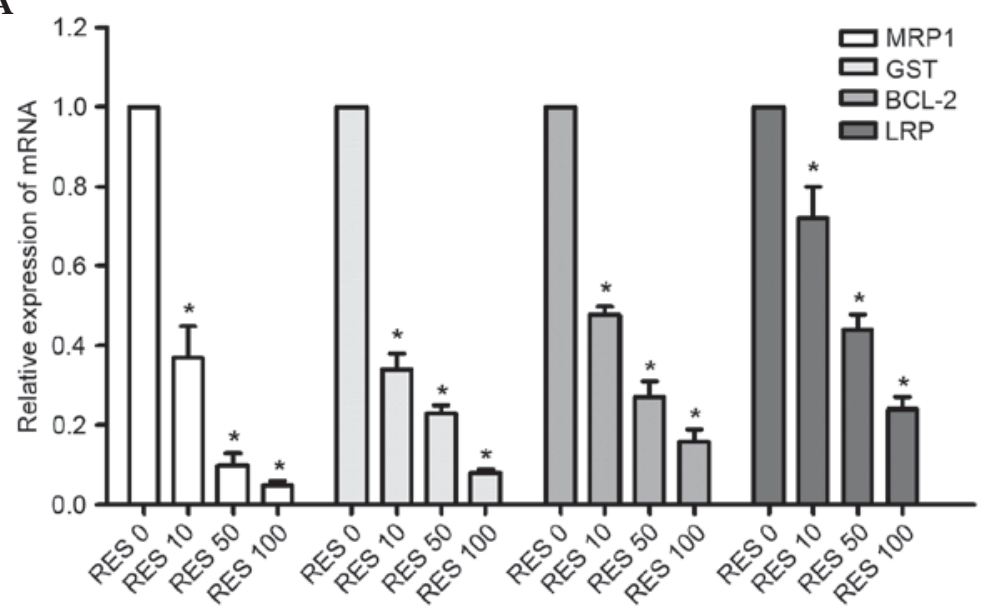

B

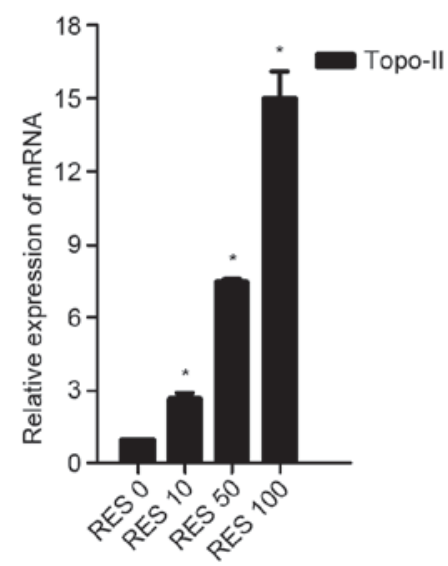

Figure 5. Relative expression of (A) MRP1, GST, BCL-2 LRP, and (B) Topo-II at the mRNA level in pumc-91/ADM cells determined using reverse transcription-quantitative polymerase chain reaction. Cells were treated with different concentrations of RES $(0,10,50$ and $100 \mu \mathrm{M})$ for $48 \mathrm{~h}$. The group not treated with RES $(0 \mu \mathrm{M})$ was considered to be the control group. Data are expressed as a ratio of target gene to GAPDH, the housekeeping gene used. ${ }^{*} \mathrm{P}<0.05$ vs. control group. MRP1, multi-drug resistance 1; GST, glutathione S-transferase; BCL-2, B cell leukemia/lymphoma 2; LRP, lung resistance protein; Topo-II, topoisomerase II; RES, reservatrol.

of MRP1, LRP, GST, BCL-2 and Topo-II were associated with protein expression in cells treated with RES (10, 50 and $100 \mu \mathrm{M})$, an immunofluorescence assay was performed. The protein expression levels of MRP1, LRP, GST and BCL-2 were reduced in the RES treatment groups $(10,50$ and $100 \mu \mathrm{M})$ in accordance with the mRNA expression levels observed. 


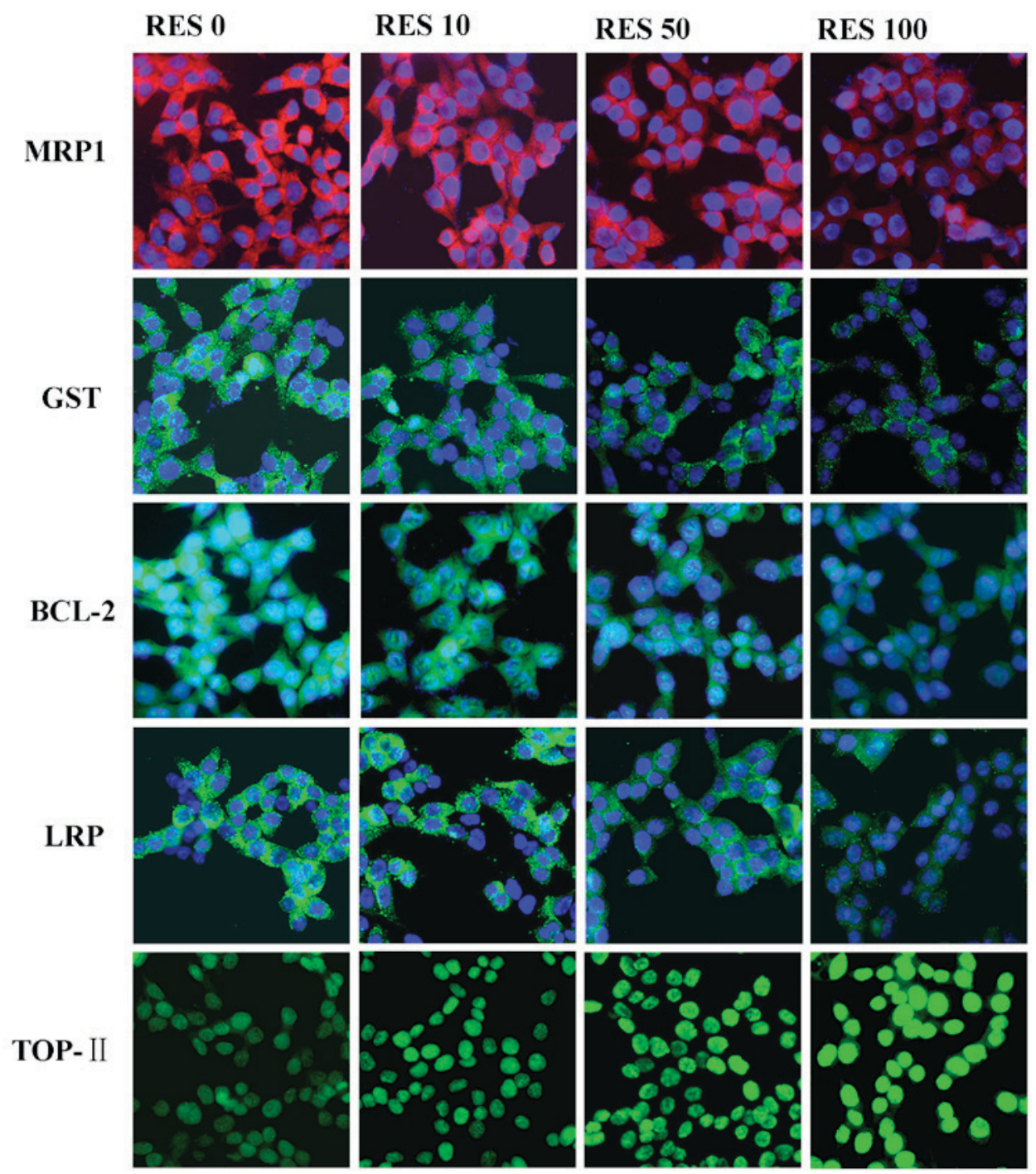

Figure 6. Protein expression levels of MRP1, LRP, GST, BCL-2 and Topo-II in pumc-91/ADM cells were examined by immunofluorescence assay. Cells were treated with different concentrations of RES $(0,10,50$ and $100 \mu \mathrm{M})$ for $48 \mathrm{~h}$. The group not treated with RES $(0 \mu \mathrm{M})$ was considered to be the control group. Magnification, x400. MRP1, multi-drug resistance 1; LRP, lung resistance protein; GST, glutathione S-transferase; BCL2, B cell leukemia/lymphoma 2; Topo-II, topoisomerase II; RES, resveratrol.

However, for Topo-II, it was demonstrated that RES enhanced the expression levels (Fig. 6). The protein expression levels of Topo-II increased gradually in RES treatment groups compared with the untreated cells. These findings indicated that RES may downregulate the expression levels of MRP1, LRP, GST, BCL-2 and upregulate the expression levels of Topo-II, in a dose-dependent manner.

\section{Discussion}

As one of the most important epithelial neoplasms worldwide, patients with bladder cancer frequently have an advanced stage of the disease at diagnosis, or experience relapse, invasion and dissemination following first-line therapy, which results in a poor prognosis (32). Improvements in clinical chemotherapy have increased the survival rate of patients with bladder cancer. However, MDR remains a major challenge for successful cancer chemotherapy as when resistance occurs anticancer drugs are unable to induce an anticancer effect. The use of higher drug doses may result in serious toxicity and a reduced curative effect (33). Additionally, MDR may be multifactorial, with at least two different resistance mechanisms against the same drug within the same tumor (34). Therefore, it is important to identify novel reversal agents with a lower toxicity, high efficiency and multiple targets.

The present study selected three herbal medicines and determined their effect on ADM resistance in pumc-91/ADM bladder cancer cells. A previous study reported that oral administration of Rh2 may inhibit the growth of ovarian xenografts in nude mice (35). A synergistic effect was observed when Rh2 and cisplatin were intravenously administered to nude mice bearing ovarian xenografts (36). Another previous study suggested that there was a synergistic effect when murine hepatoma, sarcoma and melanoma models were treated with $\mathrm{Rh} 2$ and paclitaxel or mitoxantrone (24). Previous studies have also determined that EGCG was synergistically cytotoxic to human breast and oral epidermoid cancer cells by modulating P-glycoprotein (P-gp) and the estrogen receptor $(37,38)$ The flavonoid EGCG may 
inhibit various enzymatic reactions involving ATP hydrolysis, such as phosphorylation. Drug transport by P-gp is coupled to ATP hydrolysis. P-gp actively pumps out the anticancer drug from the inside of tumor cells using ATP hydrolysis as an energetic source $(37,38)$. EGCG may also reverse cisplatin resistance by downregulation of AXL receptor tyrosine kinase and TYRO3 protein tyrosine kinase 3 in human lung cancer cells (25). The present study demonstrated that only RES was able to enhance the cytotoxicity of ADM by reversing ADM resistance of pumc-91/ADM cells; however, Rh2 and EGCG were unable to do so. The increased concentration of RES resulted in a decreased $\mathrm{ADM} \mathrm{IC} \mathrm{I}_{50}$ compared with the control group, indicating that the reversal effect of RES occurred in a dose-dependent manner. RES is a natural polyphenol and is a promising novel therapeutic substance due to its antiviral, anti-inflammatory, antioxidant, anti-aging, cardioprotective and neuroprotective properties (39). Previous studies have focused on the anti-tumorigenic activity of RES in various cancer cells, including prostate, head and neck squamous cell carcinoma, lung, ovarian, uterine and colorectal cancer (40-42). Furthermore, it has been demonstrated that RES may enhance the cytotoxicity of anticancer agents, such as doxorubicin, when used in breast and prostate cancer treatment $(43,44)$. Several drug-metabolizing genes have been identified as prognostic markers for bladder cancer therapy; therefore, the present study examined the effects of RES on their mRNA and protein expression levels. The decrease of MRP1, LRP, GST, BCL-2 mRNA levels and the increase of Topo-II levels were confirmed following RES treatment of pumc-91/ADM cells. These results were consistent with the dose-dependent effects on protein expression levels observed by immunofluorescence in pumc-91/ADM cells. These effects may be attributed to various mechanisms, including increased drug accumulation, altered cell cycle events, activated drugs, reduced oncogene expression and unaltered drug targets. In addition, cell cycle regulation is an important mechanism required for reversing drug resistance in bladder cancer. In the present study, RES may induce cell cycle arrest of pumc-91/ADM cells at $\mathrm{S}$ phase, which may be accompanied by a decrease in the number of cells in the G1 phase. The present study revealed that the use of chemotherapeutic agents in combination with RES as a chemosensitizer or adjuvant may be useful for the treatment of bladder cancer and drug resistance.

The cell ADM resistance reversal assay demonstrated that RES may enhance the cytotoxicity of ADM in pumc-91/ADM cells; however, Rh2 and EGCG could not. Additionally, a significant decrease in MRP1, LRP, GST, BCL-2 mRNA expression levels and an increase of Topo-II levels were observed in the RES-treated groups. Therefore, MRP1, LRP, GST, BCL-2 and Topo-II may be associated with the effect of RES on resistance in pumc-91/ADM cells observed in the present study. These findings demonstrated that RES may be a potential candidate for the reversal of MDR in bladder cancer chemotherapy.

\section{Acknowledgements}

The present study was funded by the Beijing Administration of Traditional Chinese Medicine (grant no. 2014-ZYJ04).

\section{References}

1. Gingrich JR: Bladder cancer: Chemohyperthermia for bladder cancer-clinically effective? Nat Rev Urol 8: 414-416, 2011.

2. Kaufman DS, Shipley WU and Feldman AS: Bladder cancer. Lancet 374: 239-249, 2009.

3. Krishna R and Mayer LD: Multidrug resistance (MDR) in cancer. Mechanisms, reversal using modulators of mdr and the role of mdr modulators in influencing the pharmacokinetics of anticancer drugs. Eur J Pharm Sci 11: 265-283, 2000.

4. Yu S, Meng Q, Hu H and Zhang M: Correlation of ANXA1 expression with drug resistance and relapse in bladder cancer. Int J Clin Exp Pathol 7: 5538-5548, 2014.

5. Meng Q, Lei T, Zhang M, Zhao J, Zhao XH and Zhang M: Identification of proteins differentially expressed in adriamycin-resistant (pumc-91/ADM) and parental (pumc-91) human bladder cancer cell lines by proteome analysis. J Cancer Res Clin Oncol 139: 509-519, 2013.

6. Hu H, Meng Q, Lei T and Zhang M: Nucleophosmin1 associated with drug resistance and recurrence of bladder cancer. Clin Exp Med 15: 361-369, 2015.

7. Gottesman MM: Mechanisms of cancer drug resistance. Annu Rev Med 53: 615-627, 2002.

8. Hong L, Piao Y, Han Y, Wang J, Zhang X, Du Y, Cao S, Qiao T, Chen Z and Fan D: Zinc ribbon domain-containing 1 (znrd1) mediates multidrug resistance of leukemia cells through regulation of p-glycoprotein and BCL-2. Mol Cancer Ther 4: 1936-1942, 2005.

9. Longley DB and Johnston PG: Molecular mechanisms of drug resistance. J Pathol 205: 275-292,2005

10. Roy S, Kenny E, Kennedy S, Larkin A, Ballot J, Perez De Villarreal M, Crown $J$ and O'Driscoll L: MDR1/P-glycoprotein and MRP-1 mRNA and protein expression in non-small cell lung cancer. Anticancer Res 27: 1325-1330, 2007.

11. Ishikawa Y, Nagai J, Okada Y, Sato K, Yumoto R and Takano M: Function and expression of ATP-binding cassette transporters in cultured human Y79 retinoblastoma cells. Biol Pharm Bull 33: 504-511, 2010.

12. Chen ZS, Furukawa T, Sumizawa T, Ono K, Ueda K, Seto K and Akiyama SI: ATP-dependent efflux of CPT-11 and SN-38 by the multidrug resistance protein (MRP) and its inhibition by PAK-104P. Mol Pharmacol 55: 921-928, 1999.

13. Khodadadian M, Leroux ME, Auzenne E, Ghosh SC, Farquhar D, Evans R, Spohn W, Zou Y and Klostergaard J: Mrpand BCL-2-mediated drug resistance in human SCLC: Effects of apoptotic sphingolipids in vitro. Lung Cancer 66: 48-57, 2009.

14. Gruber BM, Bubko I, Krzyszton-Russjan J and Anuszewska EL: Synergistic action of doxorubicin and sulindac in human cervix carcinoma cells - studies on possible mechanisms. Med Sci Monit 16: BR45-BR51, 2010.

15. Scheffer GL, Schroeijers AB, Izquierdo MA, Wiemer EA and Scheper RJ: Lung resistance-related protein/major vault protein and vaults in multidrug-resistant cancer. Curr Opin Oncol 12: 550-556, 2000.

16. Cullen KJ, Newkirk KA, Schumaker LM, Aldosari N, Rone JD and Haddad BR: Glutathione s-transferase pi amplification is associated with cisplatin resistance in head and neck squamous cell carcinoma cell lines and primary tumors. Cancer Res 63: 8097-8102, 2003.

17. Sakamoto M, Kondo A, Kawasaki K, Goto T, Sakamoto H, Miyake K, Koyamatsu Y, Akiya T, Iwabuchi H, Muroya T, et al: Analysis of gene expression profiles associated with cisplatin resistance in human ovarian cancer cell lines and tissues using cdna microarray. Hum Cell 14: 305-315, 2001.

18. Kellner U, Sehested M, Jensen PB, Gieseler F and Rudolph P: Culprit and victim-DNA topoisomerase II. Lancet Oncol 3: 235-243, 2002

19. Palaniyandi K, Zhao Q and Chang XB: Infection of H69AR cells with retroviral particles harboring interfering RNAi significantly reduced the multidrug resistance of these small cell lung cancer cells. Int J Biochem Mol Biol 2: 155-167, 2011.

20. Patel J and Mitra AK: Strategies to overcome simultaneous P-glycoprotein mediated efflux and CYP3A4 mediated metabolism of drugs. Pharmacogenomics 2: 401-415, 2001.

21. Xu HW, Xu L, Hao JH, Qin CY and Liu H: Expression of P-glycoprotein and multidrug resistance-associated protein is associated with multidrug resistance in gastric cancer. J Int Med Res 38: 34-42, 2010. 
22. Cervello M and Montalto G: Cyclooxygenases in hepatocellular carcinoma. World J Gastroenterol 12: 5113-5121, 2006.

23. Jia WW, Bu X, Philips D, Yan H, Liu G, Chen X, Bush JA and Li G: Rh2, a compound extracted from ginseng, hypersensitizes multidrug-resistant tumor cells to chemotherapy. Can J Physiol Pharmacol 82: 431-437, 2004.

24. Kim KC and Lee C: Reversal of Cisplatin resistance by epigallocatechin gallate is mediated by downregulation of axl and tyro 3 expression in human lung cancer cells. Korean J Physiol Pharmacol 18: 61-66, 2014.

25. Huang F, Wu XN, Chen J, Wang WX and Lu ZF: Resveratrol reverses multidrug resistance in human breast cancer doxorubicin-resistant cells. Exp Ther Med 7: 1611-1616, 2014.

26. Shibata S: Chemistry and cancer preventing activities of ginseng saponins and some related triterpenoid compounds. J Korean Med Sci1 16 (Suppl): S28-S37, 2001.

27. Bode AM and Dong Z: Targeting signal transduction pathways by chemopreventive agents. Mutat Res 555: 33-51, 2004.

28. Park OJ and Surh YJ: Chemopreventive potential of epigallocatechin gallate and genistein: Evidence from epidemiological and laboratory studies. Toxicol Lett 150: 43-56, 2004.

29. Shankar S, Siddiqui I and Srivastava RK: Molecular mechanisms of resveratrol (3,4,5-trihydroxy-trans-stilbene) and its interaction with TNF-related apoptosis inducing ligand (TRAIL) in androgen-insensitive prostate cancer cells. Mol Cell Biochem 304: 273-285, 2007.

30. Zhang M, Jin S and Zhang M: The establishment and biological characteristics evaluation of human multidrug-resistant bladder cancer Pumc-91/ADM cell line. J Med Res 38: 70-72, 2009.

31. Livak KJ and Schmittgen TD: Analysis of relative gene expression data using real-time quantitative PCR and the 2(-delta delta $C(T)$ ) method. Methods 25: 402-408, 2001.

32. Jacobs BL, Lee CT and Montie JE: Bladder cancer in 2010: How far have we come? CA Cancer J Clin 60: 244-272, 2010.

33. Liscovitch $\mathrm{M}$ and Lavie $\mathrm{Y}$ : Cancer multidrug resistance: A review of recent drug discovery research. IDrugs 5: 349-355, 2002.

34. Larsen AK and Skladanowski A: Cellular resistance to topoisomerase-targeted drugs: From drug uptake to cell death. Biochim Biophys Acta 1400: 257-274, 1998.
35. Nakata H, Kikuchi Y, Tode T, Hirata J, Kita T, Ishii K, Kudoh K, Nagata I and Shinomiya N: Inhibitory effects of ginsenoside Rh2 on tumor growth in nude mice bearing human ovarian cancer cells. Jpn J Cancer Res 89: 733-740, 1998.

36. Kikuchi Y, Sasa H, Kita T, Hirata J, Tode T and Nagata I: Inhibition of human ovarian cancer cell proliferation in vitro by ginsenoside $\mathrm{Rh} 2$ and adjuvant effects to cisplatin in vivo. Anticancer Drugs 2: 63-67, 1991.

37. Chisholm K, Bray BJ and Rosengren RJ: Tamoxifen and epigallocatechin gallate are synergistically cytotoxic to MDA-MB-231 human breast cancer cells. Anticancer Drugs 15: 889-897, 2004.

38. Qian F, Wei D, Zhang Q and Yang S: Modulation of P-glycoprotein function and reversal of multidrug resistance by (-)-epigallocatechin gallate in human cancer cells. Biomed Pharmacother 59: 64-69, 2005.

39. Shankar S, Singh G and Srivastava RK: Chemoprevention by resveratrol: Molecular mechanisms and therapeutic potential. Front Biosci 12: 4839-4854, 2007.

40. Heiduschka G, Bigenzahn J, Brunner M and Thurnher D: Resveratrol synergistically enhances the effect of etoposide in HNSCC cell lines. Acta Otolaryngol 134: 1071-1078, 2014.

41. Mitani T, Harada N, Tanimori S, Nakano Y, Inui H and Yamaji R: Resveratrol inhibits hypoxia-inducible factor- $1 \alpha$-mediated androgen receptor signaling and represses tumor progression in castration-resistant prostate cancer. J Nutr Sci Vitaminol (Tokyo) 60: 276-282, 2014.

42. Araújo JR, Gonçalves P and Martel F: Chemopreventive effect of dietary polyphenols in colorectal cancer cell lines. Nutr Res 31: $77-87,2011$

43. Pozo-Guisado E, Merino JM, Mulero-Navarro S Lorenzo-Benayas MJ, Centeno F, Alvarez-Barrientos A and Fernandez-Salguero PM: Resveratrol-induced apoptosis in MCF-7 human breast cancer cells involves a caspase-independent mechanism with downregulation of BCL-2 and NF-kappaB. Int J Cancer 115: 74-84, 2005.

44. Benitez DA, Pozo-Guisado E, Alvarez-Barrientos A, Fernandez-Salguero PM and Castellón EA: Mechanisms involved in resveratrol-induced apoptosis and cell cycle arrest in prostate cancer-derived cell lines. J Androl 28: 282-293, 2007. 